3. Subramanian, A. \& Qaim, M. World Dev. 37, 256-267 (2009).

4. Subramanian, A. \& Qaim, M. J. Dev. Stud. 46, 295311 (2010).

5. Marshall, A. Nat. Biotechnol. 27, 221 (2009).

6. Huang, J., Hu, R., Rozelle, S. \& Pray, C. Science 308, 688-690 (2005)

7. Gomez-Barbero, M., Berbel, J. \& Rodriguez-Cerezo, E. Nat. Biotechnol. 26, 384-386 (2008).

8. Qaim, M., Subramanian, A. \& Sadashivappa, P. Nat. Biotechnol. 27, 803-804 (2009).
9. Walker, T. \& Ryan, J. Village and Household Economies in India's Semi-Arid Tropics (The Johns Hopkins University Press, Baltimore, Maryland, 1990).

10. Sadashivappa, P. \& Qaim, M. AgBioForum 12, 172183 (2009).

11. Adelman, I., Taylor, E. \& Vogel, S. J. Dev. Stud. 25, 5-24 (1988).

12. Subramanian, S. \& Sadoulet, E. Econ. Dev. Cult. Change 39, 131-173 (1990).

13. Parikh, A. \& Thorbecke, E. Econ. Dev. Cult. Change 44, 351-377 (1996).

\title{
BIO's track record on emerging companies
}

\section{To the Editor:}

As executives at emerging biotech companies and chairs of the Biotechnology Industry Organization's (BIO; Washington, DC) Board of Directors (S.S.) and Emerging Companies Governing Board (R.K.), we were pleased to see that your editorial in the February issue ${ }^{1}$ recognized that BIO is the "only advocate for the smaller, younger, nonrevenue-driven [biotech] companies" but have to disagree that our voice on behalf of these small firms is not "always loud and clear."

BIO consistently and effectively advocates for expanding available funding for emerging biotech companies, which compose $\sim 90 \%$ of our core membership. These companies have no products on the market and revenues of $<\$ 25$ million a year, so they rely heavily on venture capital and other investors to fund the lengthy and expensive process of drug development and then regulatory approval.

BIO's advocacy agenda is often driven by its emerging companies. BIO's Emerging Companies Section Governing Board ensures that issues of unique concern to small companies are brought forward and that the voice of small companies is fully heard on issues affecting the broader membership of BIO. Emerging companies also comprise $>40 \%$ of BIO's Health Section Governing Board, which is the entity within BIO's governance structure that formally develops and sets BIO's positions on major healthcare issues.

BIO seeks public policy outcomes that help encourage investment in small, researchintensive biotech companies and advocates for public policies that expand access to, and the availability of, public funding for research conducted by these companies.
Over the past year, BIO has worked tirelessly with its members to advocate successfully for a provision included in the healthcare reform legislation recently signed into law that will provide $\$ 1$ billion in therapeutic discovery project tax credits. This credit will provide relief to investment-starved small biotech research companies by helping to offset a portion of resources spent on therapeutic development activities, such as hiring scientists and conducting clinical studies.

BIO's continuing work to restore eligibility to majority venture-backed small biotech companies to compete for Small Business Innovation Research (SBIR) grants has resulted in an important discussion on Capitol Hill about the nature of our sector's funding. We have won informed and passionate support in both the House and Senate and significant legislative progress. We remain optimistic that the SBIR/STTR Reauthorization Act of 2009 will address our concerns.

BIO successfully advocates for large and small companies alike by addressing issues specific to company size and business sector, as well as those that affect the industry as a whole. Emerging companies depend on the success of established biotech companies to get innovative new therapies approved and reimbursed at reasonable rates to attract investment.

Our advocacy efforts on healthcare reform have exemplified our success in shaping public policy so that it continues to incentivize innovation, benefiting biotech companies, both large and small.

The healthcare reform law also includes language to establish a pathway for the approval of biosimilars, which will ensure patient safety, expand competition, reduce costs and provide necessary and fair incentives for continued biomedical innovation. BIO spent the past 3 years tirelessly educating members of the House and Senate on the complexity of biologics and the importance of providing a significant period of data exclusivity to allow biotech companies to recover their expenses and provide an adequate return on investment. Without the guarantee of this return on investment, firms such as ours would have great difficulty in raising funds to finance the next-generation innovative therapies.

$\mathrm{BIO}$ also has been a leading player in advocating meaningful patent reform legislation that will help promote continued biotechnology innovation and help drive US economic growth. Patents are often the sole assets of many BIO members. As such, strong and predictable patent protection enables the flow of risk capital that is vital to achieving biotechnology's promise. While patent reform legislation continues to wind its way through Congress, BIO has successfully advocated for several key provisions that will strengthen the US patent system and enhance patent quality.

Perhaps as crucial as the issues that BIO's board chooses to advocate for is our approach. BIO has, and will continue to be, policy led. Our engagements with members of Congress are oriented around the key facts about our industry, without regard to party or politics. The industry that $\mathrm{BIO}$ represents is based on cutting-edge science, and our efforts are supported by data and facts.

In addition to its advocacy efforts on behalf of companies, BIO hosts industryleading investor and partnering meetings in the United States and around the world to provide emerging companies with investment, licensing and other partnership opportunities.

$\mathrm{BIO}$ is committed to be the voice of all biotech companies-whether small, medium or large. Although the difficulty of doing so is not lost on us, the voice of small biotech is both loud and clear-and, we are happy to report, being heard.

\section{COMPETING FINANCIAL INTERESTS}

The authors declare no competing financial interests.

\section{Rachel K King ${ }^{1}$ \& Stephen A Sherwin ${ }^{2}$ \\ ${ }^{1}$ GlycoMimetics, Inc., Gaithersburg, Maryland,} USA. ${ }^{2}$ Ceregene, Inc., San Diego, California, USA.

1. Anonymous. Nat. Biotechnol. 28, 103 (2010). 